\title{
O trabalho e A UTOPIA DA IGUALDADE SOCIAL
}

\author{
A CONSTRUÇÃO DA SOCIEDADE DO TRABALHO NO BRASIL: \\ UMA INVESTIGAÇÃO SOBRE A PERSISTÊNCIA SECULAR DAS DESIGUALDADES \\ De Adalberto Moreira Cardoso. Rio de Janeiro: Editora FGV, 2010, 463 pp.
}

JACOB CARLOS LIMA

[1] Período que podemos situar historicamente com as propostas keneysianas a partir da década de 1930 nos Estados Unidos, e os anos pósSegunda Guerra Mundial na Europa Ocidental até a crise da década de 1970 e a reestruturação econômica de corte neoliberal.
Nas últimas décadas, a sociologia tem questionado e debatido o trabalho como categoria explicativa estruturante das sociabilidades nas sociedades contemporâneas, tendo como pano de fundo as transformações econômicas e políticas do final do século xx. O fim das experiências socialistas, a crise do Estado de bem-estar social, a reestruturação da produção e a revolução tecnológica informacional reconfiguraram as relações capital-trabalho e o papel do Estado como mediador dos conflitos e regulador dessas relações. Isso não significou o fim desse papel, mas seu questionamento permanente em nome da redução dos custos da força de trabalho, da competitividade internacional etc. De forma aparentemente paradoxal, o trabalho assalariado percebido nos primórdios do capitalismo como a nova escravidão a ser combatida, foi ressignificado a partir da incorporação progressiva de direitos sociais aos contratos de trabalho. A relação de assalariamento, regulada por ganhos, jornada de trabalho, direito à saúde, educação, previdência, constituiu o bem-estar social das sociedades capitalistas avançadas como um ideal a ser alcançado de maior igualdade política, social e econômica.

A proposta de revolução operária, de uma sociedade gerida pelos trabalhadores, deu lugar ao avanço contínuo das conquistas sociais, num viés socialdemocrata, da busca da utopia da igualdade e justiça social, sem rupturas revolucionárias. Assim, conceitos como sociedade do trabalho, sociedade dos direitos, sociedade salarial, cidadania social tornaram-se explicativos de um período específico do desenvolvimento capitalista ${ }^{1}$, no qual a luta de classes assumiu novas características e a mudança social significou a incorporação crescente dos trabalhadores na ordem capitalista por meio da regulação das formas de produção e reprodução social. Trabalho e cidadania - entendidos como direitos sociais, políticos e econômicos - tornaram-se 
sinônimos, em certa medida. O conceito de trabalho, constituía-se em instrumento fundamental na compreensão e na explicação da organização da vida social de forma geral, das questões do cotidiano, à construção de identidades sociais, e dos movimentos de transformação da sociedade.

No Brasil, a sociedade do trabalho nunca se efetivou no sentido de que a maioria dos trabalhadores sempre esteve fora da cidadania regulada pelo trabalho. Como afirma Oliveira ${ }^{2}$, mais que Estado do bem-estar social, no Brasil, sempre houve um Estado de mal-estar social representado pela inclusão de parcelas minoritárias dos trabalhadores aos direitos sociais propiciados pelo trabalho formal. Entretanto, a partir da década de 1930, no governo Getúlio Vargas, a regulação das relações capital-trabalho, ainda que restrita, construiu uma expectativa de direitos sociais que marca a sociedade brasileira até hoje.

A proposta do livro de Cardoso é recuperar a construção dessa inconclusa sociedade do trabalho no Brasil, desde os momentos iniciais do Estado brasileiro até os mecanismos excludentes que o constituíram e o mantêm ainda hoje como um dos países campeões mundiais da desigualdade social. A persistência das desigualdades sociais se dá pelos padrões de incorporação dos trabalhadores ainda na nascente ordem capitalista, e se perenizam na construção das relações sociais posteriores, marcada pela fragilidade estatal, pela violência contra o trabalho organizado, pelas formas desorganizadas de inserção dos trabalhadores migrantes no mercado de trabalho urbano e pela insensibilidade das elites dominantes em relação aos "de baixo". A herança escravista de dominação e descaso com os trabalhadores persiste na nova ordem republicana que se inicia.

Esse conjunto de fatores Cardoso defende serem responsáveis por eestruturantes de uma sociedade caracterizada pela grande inércia que resulta na reprodução geracional de pobreza e desigualdades. Para ele, "o Brasil construiu seu estado de bem estar social como estado redistributivo, mas a redistribuição jamais se universalizou nem foi capaz de reduzir a pobreza a patamares socialmente aceitáveis. Não levou a uma turbulência social-revolucionária, mas uma violência circunscrita a pequenos grupos em momentos específicos da história" (p.17).

O livro apresenta um conjunto de hipóteses instigantes, visando lançar novo olhar às interpretações sobre a nossa "questão social". A proposta é ambiciosa e divide-se em duas partes recortadas temporalmente: do Império à República Velha na constituição do que seria a construção da sociabilidade capitalista e sua inércia estrutural para a mudança social; e, a partir de 1940, a construção da sociedade do trabalho na ordem social instituída por Vargas que representou uma ruptura nessa dinâmica inercial oriunda da ordem escravista, reno-
[2] Oliveira, Francisco de. "A metamorfose da arribaçã". Novos Estudos Cebrap, $\mathrm{n}^{\circ}$ 27, jul.1990, pp. 67-92. 
vando as estruturas estatais sem mexer, contudo, nas relações de trabalho no campo. Isto resultou em mudanças lentas e graduais mantendo as desigualdades. A persistência dos padrões de desigualdade social é o fio condutor que dá unidade ao livro, cujas partes podem ser lidas autonomamente.

A primeira parte, organicamente estruturada, recupera as contribuições das pesquisas da história social e do trabalho das últimas décadas, confrontando com as interpretações consolidadas. $\mathrm{O}$ autor ressalva, entretanto, que sua preocupação não é historiográfica e sim sociológica, analisando as contribuições recentes da pesquisa histórica sob o olhar da sociologia, o que lhe permitiu formular novas hipóteses. Entre estas podemos destacar a relação entre a escravidão e a "construção de uma ética do trabalho degradada, uma imagem depreciativa do povo, uma indiferença moral das elites em relação às carências da maioria e uma rígida hierarquia social marcada por grandes desigualdades" (p. 49). Fundamentando essa hipótese, Cardoso recorre a uma releitura distinta da visão clássica ou o que chama de "sãopaulocentrica", discutindo os diversos regimes de escravidão e contrapondo-se à interpretação da plantation e da escravaria a ela ligada. Bahia, Pernambuco, Minas Gerais, São Paulo e região Sul tinham situações diferentes; a plantation era restrita a algumas regiões. A imigração não seria, dessa forma, a substituição dos escravos, que em sua maioria já estavam liberados para atender as necessidades dessa mesma plantation, e de outras atividades econômicas constituindo uma massa diversificada de mestiços, dispersos e nômades. A libertação dos escravos não alterou as formas de controle social representada pelas milícias privadas nas mãos dos senhores locais com implicações políticas durante todo o período.

A coexistência do um trabalho livre e o controle social privado favoreceu o surgimento de um "Estado antissocial" marcado pela descentralização do poder controlado das oligarquias locais e regionais, inexistência de qualquer legislação voltada para a questão social.Aliás, tal questão, para as elites, "não existia", tudo o que se referia aos pobres era uma questão de polícia. A federação constituiu-se no instrumento dessas oligarquias que viviam brigando entre si, mas que se juntavam contra escravos e pobres sempre que se sentiam ameaçadas. Os interesses públicos não excediam os interesses privados, o que se manteve no início da industrialização, quando as elites industriais respondiam com repressão a qualquer ameaça grevista beneficiada com o "estado de sítio permanente que vigorou nos centros industriais mais importantes a partir de 1922, por causa das revoltas militares" (p.133).

A massa de desocupados e subocupados nas cidades favoreceu o desenvolvimento de relações de trabalho com condições precárias e baixos salários. Inicia-se a segregação espacial das cidades, a violência 
e a repressão estatal à desordem, o povo sendo culpado pela própria miséria na visão das elites. Dessa forma, constrói-se um mercado de trabalho que tem como característica estruturante a precariedade das condições de inserção, permanência e mobilidade, situação que, em grande medida, ainda se mantém.

A hipótese discutida por Cardoso de que a imigração não seria a mera substituição dos escravos, que os imigrantes ocuparam os espaços do mercado e, portanto, os capitalistas urbanos não precisaram recorrer ao disciplinamento do cotidiano para a implementação de uma educação para o trabalho é instigante e ao mesmo tempo polêmica. É possível sustentar que a situação de São Paulo foi distinta por conta do boom da cafeicultura e que os proprietários privadamente organizavam a vinda de imigrantes e os submetiam a condições de trabalho similares à da escravidão. Sem dúvida isto pode colocar em xeque a ideia da busca de trabalhadores habituados ao assalariamento e ao trabalho livre, coisa que os próprios fazendeiros não estavam. Mas ao sair de São Paulo (e mesmo em São Paulo), tendo em mente o trabalho industrial, a implementação de uma educação para o trabalho talvez não tenha sido tão irrelevante.

Basta lembrar que nesse período numerosas fábricas surgiram nas diversas regiões do país; vilas e cidades operárias foram construídas como forma de disciplinarização e imobilização de uma força de trabalho desacostumada aos ritmos e às exigências do trabalho industrial. Excluindo São Paulo e o Sul do país, o empresariado utilizou basicamente o elemento nacional, com exceção de profissionais qualificados e cargos gerenciais em alguns casos. Leite Lopes 3 (1988), em sua pesquisa sobre a fábrica Paulista no município do mesmo nome em Pernambuco, no que hoje constitui a Região Metropolitana do Recife, demonstrou o papel disciplinador e educativo pretendido pelo empresário na constituição de sua força de trabalho. Os trabalhadores eram aliciados no sertão nordestino, uma vez que já havia a preocupação (na primeira década do século $\mathrm{XX}$ ) com trabalhadores contaminados por ideologias subversivas nas fábricas do Recife, que então se constituía em importante centro industrial têxtil. O trabalho etnográfico de Lopes demonstra a construção de uma cultura operaria mediada por empresários, no sentido de uma "correta" educação operária, com igrejas e lazer programado numa versão tupiniquim das company towns norte-americanas e inglesas. Pesquisas sobre Rio Tinto na Paraíba ${ }^{4}$, outras ainda em Pernambuco5, Minas Gerais ${ }^{6}$ e São Paulo7 apontam no mesmo sentido. Essa preocupação empresarial não invalida a hipótese de Cardoso da privatização das relações capital e trabalho, mas matiza o descaso empresarial com a construção de uma disciplina do trabalho e com a degenerescência moral dos trabalhadores nativos, uma
[3] Leite Lopes, José Sérgio.A tecelagem dos conflitos de classe na cidade das chaminés. São Paulo/Brasília: Marco Zero/CNPq, 1988.

[4] Vale, Eltern Campina. Tecendo fios, fazendo história: a atuação operária na cidade-fábrica Rio Tinto (Paraíba, 1959-1964). Fortaleza: dissertação de mestrado, Sociologia, PPGHS, 2008.

[5] Lima, Jacob Carlos. Trabalho e formação de classe: um estudo sobre operários fabris em Pernambuco. João Pessoa: Editora da UFPB, 1996; Egler, Tamara Cohen. O chão de nossa casa: a produção da habitação em Recife. São Paulo: tese de doutorado, Sociologia, PPGHS/USP, 1987.

[6] Brandão Lopes, Juarez R. Crise do Brasil arcaico. São Paulo: Difel, 1967.

[7] Blay, Eva Alterman. Eu não tenho onde morar: vilas operárias na cidade de São Paulo. São Paulo: Nobel, 1985. 
[8] Santos, Wanderley Guilherme. Cidadania e justiça. Rio de Janeiro: Campus, 1979 . vez que estaria relacionada com a crescente ameaça política representada pela organização do operariado fabril nas cidades.

O ensaio finaliza apontando a revolução de 1930 e o início da construção da utopia representada pela proteção estatal presente na legislação social e trabalhista. Entretanto, a debilidade do Estado restringiu sua abrangência, o que excluiu os trabalhadores rurais, até a década de 1980, de qualquer proteção social, mas criou a expectativa de integração social de massas de migrantes que passaram a buscar as cidades como forma de melhoria de vida. Isto resultou no crescimento da população urbana e num mercado de trabalho fortemente marcado pela informalidade, ilegalidades diversas e violência que configuraram os cenários urbanos das grandes e médias cidades brasileiras.

Independentemente dos limites e de seu alcance, a legislação trabalhista varguista "instaurou um campo legítimo de disputa, cuja legitimação era o próprio Estado”, a cidadania regulada, utilizando o conceito de $\operatorname{Santos}^{8}$, com a promessa de integração social. Esta cidadania torna-se então a forma institucional da luta de classes, com o trabalhador em busca legítima por seus direitos. Inicia-se, pois, o processo civilizatório do capital, inexistente até então na construção de um Estado marcadamente antissocial. A CLT torna-se símbolo identitário. Ser trabalhador pressupõe ter carteira de trabalho, e esta simboliza acesso a direitos.

Na segunda parte do livro, o argumento da persistência das desigualdades e sua legitimação é discutido com a utilização de dados de censos demográficos, PNADs e pesquisas realizadas no âmbito do Iuperj, em 2001. São três capítulos que podem ser lidos como artigos independentes, pois trabalham com recortes específicos e utilizam metodologias distintas. O ponto central é como o mercado de trabalho urbano absorveu a massa de migrantes que correram para as cidades eem que medida essa mobilidade espacial resultou em mobilidade social atendendo as aspirações, os projetos de vida e as concepções de justiça desses trabalhadores.

No primeiro capítulo da segunda parte, são discutidas mudanças estruturais do período de 1940 a 2000 tendo como recorte a urbanização acelerada, o aumento da escolaridade e a entrada no mercado de trabalho dos jovens saídos da escola. Demonstra, nesse período, a permanência de mercados de trabalho estruturalmente precários, a manutenção de condições de trabalho e vida que indicam pouca mobilidade social, em que pese a universalização crescente do acesso ao ensino básico e mesmo a expansão do ensino superior. A hipótese defendida é que a educação teve pouca importância para esse mercado de trabalho, frustrando a expectativa da escolarização como condição de mobilidade. Nesse argumento, o autor destaca a decepção com uma escolaridade que não propiciou qualificação para o merca- 
do, marcado pelo emprego mal remunerado, de baixa qualidade e instável, seja pela informalidade, pela rotatividade utilizada pelas empresas como forma de rebaixamento da remuneração, seja pelos tipos de ocupação disponíveis etc.

Aurbanização e maior escolarização melhorou a chance de ocupação e mesmo de mobilidade para os mais escolarizados, mas a maioria deles ficou de fora, num lento processo de mobilidade em comparação com as gerações anteriores. Tal lentidão foi agravada pela reestruturação econômica dos anos posteriores, que aumentou as exigências de escolaridade sem a equivalente melhoria da qualidade do emprego. A maior escolarização teve, assim, um resultado paradoxal: a piora das condições deentrada dos jovens no mercado de trabalho, independentemente de seu perfil educacional.As afirmações baseiam-seem dados quantitativos que estabelecem tendências. É possível discuti-las, na medida em que a urbanização, mesmo que precária, significou em grande medida acesso à escolarização e mesmo certa melhoria comparativa com a estagnação do meio rural, dos trabalhadores mais pobres no que diz respeito ao acesso a bens materiais e simbólicos. Também deve ser considerado que a modernização da agricultura teve resultados não apenas na expulsão do homem do campo, mas produziu um relativo aumento de ocupações qualificadas, significando mudanças lentas em termos de mobilidades para os trabalhadores. Todavia, isso não modifica as tendências apontadas pelos dados apresentados por Cardoso em seu recorte analítico.

Suavizando a aridez dos dados quantitativos apresentados na perspectiva da estrutura de oportunidades de inserção no mercado, o capítulo seguinte busca demonstrar a fluidez existente nas trajetórias individuais nessa estrutura que, no conjunto, é pouco dinâmica. Utilizando perspectiva similar à adotada por Lahire` em seus retratos sociológicos nos quais recupera as disposições dos indivíduos e a realidade por eles reconstruídas, Cardoso recorre, com base em depoimentos, interpretação de comportamentos, práticas, opiniões e trajetórias, a dois casos exemplares de trabalhadores que "escaparam" de uma estrutura social que não favoreceria a mobilidade social.

Com Marlene, do interior de Minas, e Marcos, do interior do Ceará, Cardoso reconstrói as histórias de mobilidade. A primeira, como costureira, e o segundo, na construção civil, viraram empreendedores, por necessidade ou acaso, e conseguiram melhorar suas condições de vida e trabalho; possibilitaram a escolarização superior dos filhos e construíram um patrimônio num contexto de instabilidade econômica e política, altos índices inflacionários e desastrosos pacotes econômicos. As histórias permitem visualizar, segundo o autor, uma estrutura social relativamente aberta em baixo e mais fechada no topo. Os dois casos seriam representativos dos caminhos seguidos no processo de
[9] Lahire, Bernard. Retratos sociológicos: disposições e variações individuais. Porto Alegre: Artmed, 2004. 
[10] Guimarães, Antonio Sérgio A. "Ailusão do atalho:a experiência operária da pequena burguesia em descenso". In: Guimarães A. S., Agier, Michel e Castro, Nadya Araújo (orgs.).Imagens e identidades do trabatho. São Paulo: Hucitec, 1995.

[11] Cockell, Fernanda Flávia. Da enxada à pá de pedreiro: trajetórias de vulnerabilidade social. São Carlos: tese de doutorado, Engenharia de Produção, PPGEP-UFSCar, 2008. mobilidade. Situações diversificadas, em que capital social e acaso se juntam eliminando qualquer determinismo estrutural na análise.Para Cardoso o capital social e a estrutura de oportunidade, embora socialmente configurados, não são estanques, modificando-se contextualmente a partir de mudanças econômicas, políticas e sociais.

Situação análoga foi estudada entre operários fabris na Bahia por Guimarães ${ }^{10}$, que apontava a existência de "atalhos" utilizados por trabalhadores pouco escolarizados e qualificados na direção de melhores posições. Em algumas situações, a fábrica significou esse atalho. Nesses casos, a mobilidade geralmente era apenas horizontal, mantendo a condição "operária", mas possibilitava adquirir habilidades úteis no meio urbano e resultar em certa ascensão com melhoria nas condições de vida. Processo similar pode ser percebido na construção civil, em que a experiência vai se constituindo em qualificação. Mesmo com a maior procura dos trabalhadores que se especializaram nos canteiros de obras, a informalidade e os contratos temporários marcam as condições de trabalho, bem como a instabilidade permanente, o que compromete a mobilidade ${ }^{11}$. Em outras palavras, a fluidez da mobilidade é mediada por um mercado no qual formalidade e informalidade se imbricam estruturalmente, e os trabalhadores circulam entre eles o tempo todo, mesmo em ocupações mais qualificadas, autônomas ou "empreendedoras", perenizando a instabilidade como condição.

Por fim, o terceiro capítulo discute as concepções de justiça, da percepção da desigualdade e legitimação da ordem. Com base em dados provenientes de um survey de 2001 e em depoimentos, Cardoso conclui que a imensa maioria, principalmente dos pobres, percebe a desigualdade como uma injustiça, mas a considera legítima. De qualquer maneira, a maioria da população possui grandes expectativas de melhoria, o que aponta para a utopia brasileira de mobilidade permanente como percepção dominante.

O Estado continua sendo percebido como o grande agente da resolução da desse problema social. $\mathrm{O}$ acesso aos direitos teria garantias e a inserção seria uma possibilidade permanente. Não ter êxito é considerado questão pessoal, falta de sorte ou desígnio divino. Aqui os dados apontam que estudos sobretudo qualitativos podem aprofundar a análise de que exista uma correlação positiva na qual o Estado é percebido como instrumento para maior acesso à igualdade e à justiça.

Se é possível uma síntese, $A$ construção da sociedade do trabalho no Brasil elenca numerosas hipóteses, análises e provocações, difíceis de discorrer no âmbito restrito desta resenha. $O$ extenso período e as diversas proposições sugeridas oferecem, entretanto, numerosos insights para a análise da estrutura da sociedade brasileira, propondo novas pautas de pesquisa. 
Dados recentes sobre mobilidade social desta última década, com o crescimento e a estabilidade econômica, o aumento progressivo do salário mínimo e a implementação de políticas sociais compensatórias, trazem para primeiro plano a necessidade de mais estudos sobre as mudanças em nossa estrutura social com a diminuição, pela primeira vez em décadas, da pobreza absoluta. Nesse sentido, o livro é instrumento importante para a análise da mobilidade social e contribui significativamente para o debate a cada dia com maior visibilidade.

Lentamente a população brasileira move-se para patamares acima da pobreza absoluta e se depara com uma cidadania "regulada" mais pelo consumo do que pelos direitos. Cresce o número de empregos formais, e há maior distribuição territorial desses empregos. Discutir sua qualidade exigiria uma análise mais ampla sobre o trabalho no capitalismo contemporâneo. A informalidade, embora tendencialmente em queda, ainda representa cerca de 50\% do mercado de trabalho, sendo que a circulação dos trabalhadores entre formal e informal constituem-se em característica, digamos, estrutural. O trabalho informal também tem sido ressignificado como trabalho autônomo e empreendedor, mas aí adentramos em uma outra discussão.

A defesa dos direitos sociais vinculados ao trabalho pressupõe forte presença estatal na regulação capital de trabalho, o que decorre, em grande medida, de mobilização social e política. Mobilização complexa num quadro de flexibilização das relações de trabalho no qual os direitos sociais são percebidos como custos que comprometem a competitividade empresarial e as políticas sociais, percebidas financeiramente como ameaça ao fechamento das contas públicas.

As mudanças políticas desta década têm reforçado o papel do Estado na implementação de políticas sociais, na recuperação do salário mínimo e em outras medidas fundamentais para o maior atendimento das demandas sociais das populações mais pobres e diminuição da desigualdade social. Nossa sociedade do trabalho continua em construção e, para o bem ou para o mal, a utopia social brasileira continua passando pelo Estado. O livro de Cardoso é uma contribuição significativa para esse debate. 